Revista Iberoamericana, Vol. LXXVI, Núm. 231, Abril-Junio 2010, 443-457

\title{
ANA LYDIA VEGA Y EL GÉNERO NEGROGÓTICO
}

POR

PERSEPHONE BRAHAM

University of Delaware

El precursor menos reconocido de la novela negra es el género gótico, nacido en Inglaterra en 1764, con El castillo de Otranto de Horace Walpole. Durante medio siglo, la literatura gótica gozó de una descomunal popularidad, tal vez por rechazar las obsesiones racionalistas de la Ilustración a favor de la sensación, el misterio, lo sobrenatural y -sobre todo- el acoso psicológico o sexual. Fue por medio de los cuentos de Edgar Allan Poe que el gótico inició su transformación hacia la literatura de misterio y suspenso, camino al género negro.

Ambos, el negro y el gótico, son géneros desprestigiados por las presunciones vanguardistas, así como por su asociación con la literatura pulp, los folletines y penny dreadfuls de finales del siglo xix y, sobre todo, por los escritores mediocres que maltrataban, y siguen maltratando, los mecanismos ineludibles de la literatura de géneros. En Hispanoamérica, los dos géneros sufren el estigma accesorio de no ser autóctonos, una calificación irreparable para la crítica hispanófila durante la mayor parte del siglo xx. Incluso la llamada generación del '68, cuyos integrantes se encargaron tan esmeradamente de derrocar las ontologías e historias totalizadoras de sus padres, se manifestó ambivalente frente a la literatura de géneros.

El gótico es generalmente caracterizado como una literatura femenina; lo negro, según la misma lógica, es masculino. Se aducen varios criterios temáticos y formales al distinguir los géneros: la razón versus la sinrazón, el orden versus el misterio, la narrativa pulcra y matemática versus la narrativa atmosférica y poética. La novela gótica fue condenada como enviciadora de mujeres débiles; la detectivesca, como entretenimiento pasivo y pueril de imaginaciones limitadas. La novela gótica tiene por protagonista a una mujer desamparada; la novela negra reelabora el héroe de la novela de caballerías: es activo, viril e independiente. Las divergencias putativas entre los dos géneros repiten en plano menor las divergencias entre masculino y femenino, lo moderno y lo pre o a-moderno, la metrópoli y la colonia, y Europa y el Caribe. 
Edgar Allan Poe es, generalmente, llamado el padre de la narrativa detectivesca. Al mismo tiempo, sus cuentos de horror son modelos del género gótico. Fue Poe el que refutó la necesaria separación de matemático y poeta y los concilió en la figura del gran detective C. Auguste Dupin, y fue Poe el que acopló el crimen artístico y el ambiente gótico en "La caída de la Casa Usher", "El barril de Amontillado" y otros cuentos. Separados durante casi dos siglos, lo negro y lo gótico se reúnen de nuevo en varios cuentos de la escritora puertorriqueña Ana Lydia Vega. En particular, las narrativas que se suman al cuento "Pasión de historia", de Pasión de historia y otras historias de pasión (1987), invitan una exploración de las correlaciones y bifurcaciones de los dos géneros, así como los móviles de la autora al combinarlos.

El título de Pasión de historia y otras historias de pasión alude a las dos pasiones de la autora: la pasión investigativa que la lleva a escribir un texto como Falsas crónicas del sur (1991), sobre las versiones (muchas veces góticas) de la historia puertorriqueña, y la pasión por las historias de crimen y horror, a las que se confiesa adicta (Hernández y López Springfield 820). Tal vez el título sea también un tributo a la Historia de Pasión (1917) de Miguel de Unamuno: la historia del asesinato de Abel Sánchez por el Caín envidioso, Joaquín Montenegro. El texto de Unamuno es una alegoría de la "lepra nacional” de la sociedad española, la envidia; a lo mejor Vega quiere sugerir que el vicio nacional de Puerto Rico es el silencio sobre ciertos aspectos de su historia e identidad. El proverbial esqueleto en el armario, la loca en el ático, el fantasma en el pasillo, son los escándalos históricos encerrados en la mitología identitaria.

Vega es una maestra del ars combinatoria del neologismo, categoría verbal que le permite exponer las afinidades ocultas entre géneros, conceptos y fenómenos sociales. En este espíritu se ofrece el término "negrogótico" para describir los cuentos de Pasión de historia, porque invoca los múltiples planos retóricos empleados en la narrativa. El prefijo "negro", prestado del género negro o detectivesco, alude asimismo al humor negro del cuento y a la hibridez (o mejor dicho, mulatez) de texto y tema. Mediante la astuta recombinación de elementos góticos y negros, Ana Lydia Vega elabora una crítica no sólo de los términos de los discursos colonialistas y paternalistas, sino de las dicotomías -tan asentadas como apócrifas- que los sustentan. El negrogótico subraya las equivalencias formales y temáticas entre negro y gótico al plantear la tesis de que una mujer que se atreve a imaginarse como detective (lector científico e intérprete de una historia) corre fatalmente el riesgo de terminar muerta de su propia narrativa.

Revista Iberoamericana, Vol. LXXVI, Núm. 231, Abril-Junio 2010, 443-457
ISSN 2154-4794 (Electrónico) 
Ana Lydia Vega y La nOvela NEGRa

La novela policíaca en general (la novela tradicional anglosajona) suele tener como eje central una búsqueda de la verdad. Se presenta el crimen en un escenario circunscrito, un grupo limitado de sospechosos y una serie de acontecimientos que aclaran u oscurecen la verdad. La literatura de finales del siglo xix tenía celebradas como herramientas de investigación a las disciplinas positivistas de la ciencia forense, los órganos de la ley y el uso del raciocinio. En la novela policíaca moderna, la pregunta central de quién lo hizo (o, cómo lo hizo), y su correspondiente respuesta, existe en una perfecta simbiosis cuyo signo, o nexo, es la pista (clue). El placer de la lectura radica en los arabescos intelectuales que describió Fredric Jameson: las interpretaciones -ligeramente equivocadas- que se desprenden de este signo, o serie de signos, hasta que quede descartado, ante detective y lector, todo lo que no sea parte del retrato total y verdadero del crimen. ${ }^{1}$

Walter Benjamin advirtió que la narrativa de crímenes necesita de una figurasujeto que se interponga entre los hechos del caso y el lector. Es por los ojos de este personaje central, científico y fidedigno, que se lee el texto delincuente y se arman las especulaciones en cuanto a la identidad y las acciones del criminal. No es sino a través de su inteligencia que se filtran y se ordenan impresiones, pistas y datos concernientes al asunto. La novela negra norteamericana depende también de esta relación simbiótica. Sea un Sam Spade o un Archie Goodwin, un Watson o incluso un Belascoarán, esta figura representa una fuerza organizadora y constitutiva para el texto. Con todo, el detective o el intelecto que soluciona el misterio puede ser de otra persona, un genio -Sherlock Holmes, C. Auguste Dupin o Nero Wolf- cuyos ejercicios de raciocinio quedan sutilmente fuera del alcance de su compinche y del lector. Por consiguiente, el mismo proceso de deducción se convierte en otro misterio, y el lector se reduce a una especie de intérprete-manqué, desprovisto del acceso necesario para evaluar debidamente los datos.

A diferencia de la novela clásica, que se enfoca más en el aspecto enigma del crimen que en sus orígenes y corolarios éticos, la novela negra es un género de denuncias. Por eso es que se cree a la forma detectivesca más apta para la adopción hispana. Cuando Enrique Anderson Imbert hizo la pregunta, "Why are detective stories written in English? Could it be because only in civilized countries is there an aversion to violent death?” (47) muchos críticos hispanoamericanos ya dudaban de la relevancia del crimen ficticio en un contorno que consideraban

1 Fredric Jameson comentó que en la novela negra de Chandler "the empty, decorative event of the murder serves as a way of organizing essentially plotless material into an illusion of movement, into the formally satisfying arabesques of a puzzle unfolding” (124).

Revista Iberoamericana, Vol. LXXVI, Núm. 231, Abril-Junio 2010, 443-457
ISSN 2154-4794 (Electrónico) 
congénitamente bárbaro. ${ }^{2}$ Más recientemente, cuando un periodista le pregunta al escritor mexicano Juan Hernández Luna sobre el realismo del género a finales del siglo $\mathrm{xx}$, éste le responde que "ignora si la literatura se nutre de la realidad, porque lo real siempre supera a la fantasía" (Cisneros Morales). De la misma manera en la que los detectives norteamericanos hard-boiled buscan la justicia en un mundo corrupto y hostil, los detectives hispanos se encuentran aislados y enajenados por ello. Los detectives Mario Conde (de Leonardo Padura), Héctor Belascoarán Shayne (de Paco Ignacio Taibo II) y Pepe Carvalho (de Manuel Vázquez Montalbán) son detectives que comparten tanto los defectos y las debilidades, como el terco idealismo de un detective de Chandler o Hammett. Resulta seductor insinuar que la novela negra es más idealista en Hispanoamérica por la sencilla razón de su posible irrelevancia. Pero en un caso extremo, este idealismo los califica de locos: quijotes de la edad moderna.

La deuda de Ana Lydia Vega con la novela negra es obvia. Pasión de historia y otras historias de pasión fue escrita durante un período de mucha actividad en el campo detectivesco. A partir de los 1970s existía ya un boom de la novela negra en España, México y otros países hispanos. Escritoras como Sue Grafton y Sara Paretsky empezaban a escribir detectives femeninas en el molde de Raymond Chandler o Rex Stout en los ochentas.

A la misma vez, entre los hijos del '68 internacional (la generación del setenta puertorriqueña) prevalecía una postura de irreverencia y nostalgia simultáneas por los géneros literarios populares. El concepto bakhtiniano de la parodia como un instrumento de la resistencia subalterna gozaba de una descomunal influencia en la crítica posmodernista. Rosario Ferré había publicado hacía un año su parodia de la mentira nacional identitaria en Maldito amor, y en cada momento los jóvenes escritores comprobaban que la parodia ofrecía una gama de posibilidades para desmentir las tesis totalizadores en el contexto hispano. Como escritora y profesora, Ana Lydia Vega no pudo evitar estas influencias, y fue inevitable que una crítica calificara su obra de "detectivesca femenina posmoderna" (Rosell).

Pero, a pesar de sus toques posmodernistas (la intertextualidad, los juegos de género, las acotaciones implícitas y explícitas a la cultura popular y, sí, los toques paródicos), Pasión de historia no es, exactamente, una parodia. Una parodia posmoderna al estilo Bakhtin supone la apropiación de elementos formales para comunicar un contenido moral ajeno y, posiblemente, problemático con respecto al mensaje del modelo original. Si bien Vega traspone elementos de la novela negra a un contexto putativamente inapto (las calles de San Juan por las de Los Ángeles o

2 No se quiere sugerir que esta reticencia limitara la producción detectivesca de Anderson Imbert, cuyas historias policiacas son excelentes.

Revista Iberoamericana, Vol. LXXVI, Núm. 231, Abril-Junio 2010, 443-457
ISSN 2154-4794 (Electrónico) 
Nueva York, una detective por un detective, el Caribe de los años ochenta por los Estados Unidos de los treinta y cuarenta), el comunicado moral es decididamente el mismo de siempre: la denuncia de la injusticia, la defensa de los desamparados y la complicidad de los sistemas jurídicos y sociales en el asedio a las víctimas.

Pasión de historia y otras historias de pasión es un texto que desafía la noción del género en varios niveles. Puede ser leído como una sencilla recopilación de cuentos; como una novela episódica que alegoriza la nación de Puerto Rico en términos genéricos (el estado mismo es de género problemático); o dos novelas cortas (novellas) de detección en las que se busca, respectivamente, la justicia para una mujer desaparecida y la recuperación de una patria abortada el 23 de septiembre de 1868. El tema del asesinato -literal, de una persona y, figurativo, de una historiaes lo que vincula el primer cuento con el cuento final del volumen.

La obra es dedicada a William Irish (o Cornell Woolrich, el conocido autor de la novela negra The Phantom Lady, sobre un hombre condenado por el asesinato de su mujer), a Ernesto Sábato y a “todos los traductores del silencio." El texto "Sobre tumbas y héroes” es la historia de una pasión historiográfica, en la que se persigue rescatar, para la conciencia nacional, a los mártires de la causa independentista. Se trata de una tarea detectivesca y quijotesca: "un sujeto que se sabe folletín de caballería boricua, pero sigue buscando las tumbas de sus héroes en una búsqueda irónicamente heroica” (Alberty Fragoso).

Todos los otros cuentos del volumen tratan el así llamado crime passionel, sea de modo oblicuo ("Tres aeróbicos para el amor") o directo ("Pasión de historia”, "Ajustes S.A.”, “Caso omiso", "Serie negra”). En particular, los cuentos "Pasión de historia” y "Ajustes, S.A." son protagonizados por mujeres que se imaginan detectives, pero que terminan siendo las víctimas del mismo crimen que investigan. En este detalle, repetido con insistencia barroca por la autora, radica la trascendencia del elemento gótico.

\section{Novela GÓTICA}

El tema central e implícito del género gótico es el femicidio, o la violencia contra la mujer por ser, precisamente, mujer. La investigadora Kari Winter comenta sobre la conexión entre el gótico femenino y la vulnerabilidad experimentada a nivel cotidiano por una mujer en la sociedad patriarcal: "female Gothic novelists uncovered the terror of the familiar: the routine brutality and injustice of the patriarchal family, conventional religion, and classist social structures" (91). A pesar de que las historias góticas generalmente se desarrollan en un escenario algo excéntrico, el mensaje trascendental es que las mujeres son víctimas de las normas y estructuras aparentemente constituidas para salvaguardarlas en su ambiente rutinario.

Revista Iberoamericana, Vol. LXXVI, Núm. 231, Abril-Junio 2010, 443-457
ISSN 2154-4794 (Electrónico) 
Los parámetros básicos y elementos arquetípicos de la novela gótica son: una mujer (virgen, bella y joven) sin familia (implícitamente, padre, esposo, hermanos) para protegerla y ubicarla en un matrimonio (respetabilidad, seguridad económica) viaja desde lejos a un caserón-o mejor, un castillo laberíntico-poblado por personas raras, de las cuales el más sobresaliente es el amo. Éste es generalmente viril, tirano y un poco sádico. La mujer está enajenada por sus prójimos no sólo por la ambigüedad de su estatus social, sino también porque éstos tienen algo que esconder. Es este secreto o misterio que la protagonista descubre e intenta deshilvanar a lo largo de la historia. No obstante, la solución implica la destrucción de la protagonista.

Tal como en la novela negra, el eje de la trama gótica es la persecución de una verdad implícitamente vedada en un ambiente oscuro y hostil. La protagonista gótica nace la misma función de enfoque e intérprete de datos inexplicables que el protagonista detectivesco. La novela gótica con frecuencia pone en tela de juicio la cordura del sujeto central, así como sus capacidades de raciocinio y discernimiento, atribuibles, en otros contextos, al detective o sujeto “fidedigno”. Consecuentemente, la relación del lector con esta protagonista es estructuralmente idéntica a la relación con un Watson, con la única excepción de que la perspectiva del lector es limitada por un fenómeno psicológico o sobrenatural en vez de social.

PASIÓN DE HISTORIA

Aunque las dedicatorias de Pasión de historia y otras historias de pasión sean detectivescos, es igualmente manifiesto su parentesco con el género gótico. El texto epónimo del volumen reescribe Ancho mar de los sargazos de Jean Rhys. Esta novela, a su vez, interrogó los discursos raciales y genéricos de la narrativa gótica colonial al reescribir la famosa Jane Eyre de Charlotte Brontë desde la perspectiva de la mujer maniática de Rochester, Bertha Antoinetta Mason. En Jane Eyre, Bertha es caribeña. Al igual que el arquetipo colonial Calibán, ella es violenta, lujuriosa, y sólo ruge en vez de hablar: "The maniac bellowed: she parted her shaggy locks from her visage, and gazed wildly at her visitors” (Brontë 258). Jean Rhys, nacida en la isla Dominicana, recrea los antecedentes de esta locura desde sus orígenes antillanos para analizar la dinámica colonial a través de la relación de Bertha/ Antoinetta con Rochester. La novela se narra en la voz de Antoinette, dando una representación muy diferente de los mismos acontecimientos mediante esta ligera desviación de énfasis.

Siguiendo al modelo de Jean Rhys, Ana Lydia Vega se propone recuperar una historia perdida y dar voz a la "otra” desaparecida. Según desarrolla el asunto, esta otra podría ser una mujer fallecida, una mujer silenciada por el patriarcado familiar; una realidad social callada detrás de los mitos populares o, incluso, la protagonista

Revista Iberoamericana, Vol. LXXVI, Núm. 231, Abril-Junio 2010, 443-457
ISSN 2154-4794 (Electrónico) 
misma. Al igual que la novela gótica, "Pasión de historia” representa una alegoría de las relaciones sociales. Las tres mujeres se descubren en sistemas cerrados que repiten aspectos de la historia del sistema colonial en el Caribe, así como la tradición de las relaciones de género en Puerto Rico. Abundan las citas de obras góticas y personajes sádicos: Daphne Du Maurier, Blanca Nieves, Gilles de Rais, así como las alusiones a Flaubert y François Mauriac, ambos autores famosos por sus retratos de mujeres asfixiadas por los rituales de la vida burguesa.

El argumento consiste en tres historias de mujeres desaparecidas, encebolladas una dentro de otra. Carola, una joven escritora que acaba de escaparse de una relación opresiva con un hombre casado, ha conseguido por fin su "muy woolfiano cuarto propio" -en efecto, un espacio de enunciación femenino. Se interesa en la historia de una mujer asesinada en un crimen pasional, el “caso Malén”, por la cual muy pronto desarrolla una verdadera obsesión. La comunidad culpa a Malén de su propio asesinato a manos de un ex amante, dando a entender que "con razón túvole que pasar lo que le pasó" y "por estar rezando no fue” (11). Carola se horroriza ante el espectáculo de la mujer agonizando sola en el pasillo del condominio, sin que ninguno de los vecinos le abriera la puerta. El texto está repleto de neologismos y expresiones populares que manifiestan la pugna retórica entre la perspectiva feminista (los neologismos irónicos de la narradora) y la perspectiva misógina vigente (mujeres "chochicalientes" a las que los hombres matan por deber: "la piqué porque me la pegó” 11).

Según una crítica, "the Gothic novel is generally understood to serve a fundamental human need, partly what Virginia Woolf called 'the strange human need for feeling afraid'” (Prendergast 1). De manera similar, el género negro responde al deseo igualmente humano de experimentar la violencia desde la seguridad del sillón. A Carola le fascina la historia de Malén por este mismo aspecto: "tan de otro mundo sí: de hombres vengativos y mujeres prohibidas que, por algún retorcimiento clandestino, asusta pero gusta" (11). Se equivoca, sin embargo, al tratar la historia de Malén como una fábula detectivesca, buscando en las fotos y declaraciones "el hilo que las pusiera a significar" (11), en vez de comprender que el femicidio es un fenómeno fundamentalmente gótico. Cuando una vecina le advierte a Carola de que un ciclista la está espiando, Carola se identifica errónea e irónicamente con la femme fatale del género negro. Al descubrir que se trata de su antiguo amante -la protagonista asoma el "hocico" para averiguar que él ha descubierto el nuevo "habitat” (13)-, su lenguaje pronostica su verdadera situación de víctima frente al macho depredador.

Carola huye del acoso, ostensiblemente, para visitar a su antigua amiga Vilma en su "paraíso exótico", el sur de Francia. De nuevo se engaña pensando que mediante este viaje se transformará de una "triste criatura de los Trópicos" u objeto

Revista Iberoamericana, Vol. LXXVI, Núm. 231, Abril-Junio 2010, 443-457
ISSN 2154-4794 (Electrónico) 
de la investigación científica, masculina y europea en una detective de tradiciones humanas o antropóloga anticolonial (13). En Francia, se enfrenta a un gabinete de curiosidades; especímenes de la europeidad, en un ambiente que se convierte rápidamente en un gabinete de horrores.

Carola llega de noche al caserón de piedra; desde un principio, encuentra perjudicada su capacidad para leer el ambiente por el idioma, el vino que tan abundantemente le sirve el paterfamilias "Don Boina" y un catarro que la deja cada vez más enajenada de sus propias capacidades racionales. El primer día se destruyen las ilusiones del Mundo Viejo civilizado cuando se entera de que "el marido de Vilma dejaba de niño de teta al más vil de los machistas insulares” (16). "Don Boina" es el arquetípico viejo francés cuya amabilidad oculta una monstruosa inercia intelectual; su mujer es Mrs. Danvers reencarnada; Paul, el marido de Vilma, es un cazador sádico al que Carola denomina "Barba Azul”; y la propia Vilma -“la princesa taína” encerrada por los celos del esposo- se convierte poco a poco en otra Bertha Mason ante la mirada alucinada de su amiga.

Helene Myers observa que la paranoia experimentada por la heroína gótica ante una situación amenazante y ambigua bien puede funcionar como defensa. La noción de la mujer como víctima inevitable de la violencia cultural, explica, "can veer into a form of cultural essentialism that forecloses female agency and resistance" (87). Siempre son las mujeres más incautas (e implícitamente, inmodestas) las que inauguran la carnicería en las películas de horror. Vega interroga esta conjetura en las figuras de Carola, la mujer "detective”, paranoica e intelectual; y Vilma, la mujer "misterio",cuya sensualidad la hace cómplice de su propia represión. Vilma es una (estereo)típica mujer antillana, el tipo más codiciado en los poemas de Luis Palés Matos: Vega la describe como una "mamífera isleña", de "nalgamenta boricua" y "tembandúmbico andar"; Carola es de piel "amarillo hepatitis" y pelo "plagado de horquetillas". Vilma es la víctima más evidente, pero Carola no se escapa tampoco.

Carola no sabe cómo juzgar las historias que le cuenta Vilma sobre el acoso que sufre a manos de la familia de Paul, precisamente porque le parecen cuentos góticos: "la cosa sonaba tan extraña, tan conspiratoria, tan Daphne Du Maurier, que llegué a pensar que se trataba de una fantasía paranoide de mi amiga” (17). La protagonista sigue escribiendo su historia de Malén, asediada a su vez por Vilma con sus cuentos atrozmente detallados de abusos matrimoniales, los que se añaden al aturdimiento de la heroína: "lo peor era el efecto que tenían en mi percepción de la realidad inmediata. Todo se deformaba" (20). En medio de su confusión se introduce la historia de otra mujer adúltera desaparecida, Maité. Su nombre alude a la mujer abnegada del rey Louis XIV, cuya muerte en circunstancias dudosas provocó muchos chismes maliciosos en la Corte. Su ausencia nos recuerda la ausencia de Malén, la magdalena.

Revista Iberoamericana, Vol. LXXVI, Núm. 231, Abril-Junio 2010, 443-457
ISSN 2154-4794 (Electrónico) 
En esta coyuntura, la historia sufre un cambio de piel genérico, dejando la narración en primera persona por una narrativa epistolar. El efecto es doble: se exacerba la distancia entre el lector y la narradora y se evoca la memoria de la máxima heroína del género epistolar, la pobre Clarissa de Samuel Richardson, secuestrada por capricho del malvado Lovelace y encarcelada -por móviles de lucro- por su propia familia. Lovelace es el epítome del macho misógino, para el cual la modestia de una mujer sólo provoca el desdén y la lujuria: "Oh she may threaten, she may weep, she may rave 'Oh traitor! Oh fiend!' but little by little she comes to like her little cage”. Según esta perspectiva la mujer es el cómplice inevitable de la violencia cometida sobre ella. El estilo epistolar deja huecos en la historia que obstaculizan la solidaridad de lector y narrador; dejando aquél en un limbo hermenéutico. Perdida en su laberinto de historias, Carola se siente cada vez más como rehén y los huecos entre los datos registrados se ensanchan.

La indiscreción de Vilma acrecienta hasta asumir proporciones monstruosas, terminando en un adulterio con el médico vecino (llamado Jean-Pierre Rousseau, como para aludir a Jean Jacques Rousseau, el filosófo autor del Buen Salvaje). La intemperancia femenina que lleva al encierro es un elemento clave de lo gótico: Rochester dice de su primera mujer que se casó con ella porque "my senses were excited". La locura de Bertha se manifiesta mediante una sexualidad "unchaste ... gross, impure, depraved". Bertha Mason era una mujer criolla, de las colonias británicas en el Caribe. Desde la perspectiva de la metrópoli, representa la sensualidad, el atavismo y la corrupción de la colonia; según Rochester, él es la víctima de un complot criollo (gótico) para encadenarlo: "Bertha Mason is mad ...she came of a mad family; -idiots and maniacs through three generations! Her mother, the Creole, was both a mad woman and a drunkard!-as I found out after I had wed the daughter: for they were silent on family secrets before” (Brontë 249). Paul también se presenta como la víctima de una conspiración criolla, explicándole a Carola que Vilma "se inventa cosas... nunca se ha acostumbrado acá, siempre está nerviosa, de mal humor y cuando se entusiasma su alegría tampoco es natural” (29). Al final, Bertha sufre el destino de toda mujer lujuriosa -la muerte en un incendio infernaly Jane, que dominó su pasión por Rochester acatando a la moralidad imperante, se lleva la palma. En este caso, un Rochester cegado por el fuego que cauterizó la herida vital, Bertha.

Una variante importante del género gótico es el gótico americano, también conocido como "Southern gothic". Este subgénero se caracteriza por una preocupación por la cuestión de la raza. Ana Lydia Vega explora este género explícitamente en la novela corta El baúl de Miss Florence (de Falsas crónicas del Sur), sobre las peripecias de una institutriz inglesa en una hacienda puertorriqueña. Al hablar de Miss Florence, la autora alude a la importancia de la trama gótica sin advertirlo directamente:

Revista Iberoamericana, Vol. LXXVI, Núm. 231, Abril-Junio 2010, 443-457
ISSN 2154-4794 (Electrónico) 
I wanted at the same time to parody and break from the 19th century narrative model in women's writing which one finds in writers like the Brontës [...] (822). I wanted to show how an independent woman who had her own career as a tutor, who came from England where feminism was developing at the time (although it was the Victorian era) could, within the institutions of slavery, fall into a state of psychological bondage. What we see then, is this process within Miss Florence to liberate herself. (Hernández 821)

En el gótico americano, el misterio central a menudo trata las opresivas relaciones de género y raza en el ambiente de la hacienda y el esfuerzo por ocultar la "mancha negra” en una familia. En Miss Florence Vega utiliza este modelo para criticar la supresión de la identidad negra en la historia oficial puertorriqueña.

[...] On the other hand, you learned absolutely nothing about our African heritage because it was “taboo.” It was completely concealed. So, I thought that in order to achieve our own personal liberation, it was mandatory to begin the process here, in a search for the hidden history, a search for our roots, and to underscore these roots as well. (Hernández 824)

La heroína gótica, típicamente, sufre de dudas concernientes a su propia identidad: "All the imprecision and vagueness typical of Gothic description and setting serve these central dislocations of outer and inner mystery. The heroine, for example, is conventionally isolated in gloomy places that compound nameless fears about her heritage, her suitors and herself” (daVinci 206). Para Ana Lydia Vega este modelo ofrece la oportunidad de señalar la problemática identidad de los antillanos, en particular de los puertorriqueños (la mamá de Carola es adicta de la Porcelana). A la misma vez, Vega subvierte el auto odio del sujeto colonial al invertir la perspectiva, revelando así el salvajismo de la cultura metropolitana.

Cuando por fin Carola reanuda la narración regular -“aquí calla el diario y sigo yo” (31)-, es para anunciar su próxima "liberación” de la casa en Bordeaux y presenciar el encierro vengativo de Vilma. Paul le muestra su álbum de trofeos, en el cual sobresale una foto de Vilma con la cara junto a la cabeza de un sarrio muerto. Las dos mujeres comparten un día libre de la presencia opresiva de Paul y los suyos, pero para Carola el placer se tiñe de aprehensión. De vuelta a la Isla, Carola espera en balde la respuesta a una carta para Vilma, pues le es devuelta: Vilma ya desapareció.

El recuento entero de Carola se publica bajo un epitafio editorial que anuncia la muerte de la escritora a manos de “un desconocido”. El nombre de la editora, Griselda Lugo Fuentes, es un homenaje a la Griselda paciente de Boccaccio y Chaucer: una mujer que sufrió interminables pruebas de su constancia a manos de un marido

Revista Iberoamericana, Vol. LXXVI, Núm. 231, Abril-Junio 2010, 443-457
ISSN 2154-4794 (Electrónico) 
celoso (y tal vez la colega de la autora, Carmen Lugo Filippi). Así como la fábula de Griselda, la novela gótica termina muchas veces con el matrimonio y consiguiente rescate social de la heroína. Esta recuperación de la identidad burguesa acompaña la aclaración de todos los misterios. EnEl baúl de Miss Florence, la liberación personal y sexual de la protagonista acompaña la revelación de la verdad de las relaciones opresivas en la familia, así como en la plantación. En Miss Florence, el elemento clave es precisamente esta calidad libertadora de la actividad investigadora y el descubrimiento de verdades silenciadas. Cuando Miss Florence sale de su infierno antillano, se ha convertido en una mujer mucho más fuerte y segura.

En los cuentos de Pasión de historia y otras historias de pasión, sin embargo, el infierno gótico no lleva a la redención, y la muerte de la protagonista se revela al final como un destino ineludible y universal. La metáfora de la caza es constante en "Pasión de historia". Aparte las cabezas de jabalíes en los dormitorios, Carola se imagina amenazada no sólo por su ex amante Manuel, sino también por el médico que la ausculta (el putativo amante de Vilma) y el esposo de su amiga, el cual trata de trabar amistad con ella. Para Carola, “el muy woolfiano cuarto propio” se convierte en el cuarto del Yellow Wall-Paper de Charlotte Perkins Gilman: una prisión en la que la protagonista pierde la autonomía, la razón, la voz y la vida.

En un momento de extenuación editorial, Carola se pregunta: “¿Quién contaría a Malén, quién diría la verdad, si ella estaba muerta?” (23). Para Carola y sus compañeras, queda truncada la búsqueda de la verdad, así como la voz de la denuncia. La propia identidad femenina se revela como un obstáculo para su realización vital.

EL GÓTICO, EL FEMICIDIO Y LA NOTA ROJA

"Pasión de historia” desarrolla una compleja trama enmarcada por una historia de nota roja. Como apunta Helene Myers, "femicide -the killing of women- is a cultural convention" no sólo en la literatura, sino en la sociedad en general (1). Sus imágenes - "those women they were always finding strewn about ravines or scattered here and there in green garbage bags"- se han convertido en un lugar común de los diarios y tabloides. El horror de un crimen se convierte fácilmente en un objeto para el consumo popular, y más cuando se trata de la consabida "historia de pasión”. Hugo Sáez comenta sobre este gusto perverso por la "nota roja chic": "Con fruición, y a veces solapado asco por nuestra debilidad, devoramos noticias que difunden ignominiosos hechos de sangre...Muerte y amor son desde remotos tiempos materia de leyenda, y marchan asociados con emociones muy fuertes" (1).

Tal como los géneros negro y gótico, la nota roja se considera un género ínfimo, adecuado para el consumo popular pero no para el gusto formal de la

Revista Iberoamericana, Vol. LXXVI, Núm. 231, Abril-Junio 2010, 443-457
ISSN 2154-4794 (Electrónico) 
élite, porque sin embargo, la nota roja tiene el mismo propósito que los otros géneros populares al exponer el salvajismo humano desde una perspectiva alejada y teóricamente objetiva. Es más: la nota roja trata acontecimientos reales como si fueran ficciones, elaborando los detalles picantes y sensacionales para seducir al público en sus más bajos instintos. Tal como el género gótico femenino se considera inferior al género fantástico masculino, la nota roja femenina se considera inferior al true-crime masculino, cuyos autores se cuentan entre los grandes de la literatura norteamericana y latinoamericana: Truman Capote, Norman Mailer, Rodofo Walsh, Jorge Ibargüengoitia, Gabriel García Márquez...

Vilma llama las noticias políticas de Puerto Rico el "chisme nacional”. Con "Pasión de historia”, Ana Lydia Vega se propone elevar el "chisme” de la nota roja -y de la vida y la muerte femeninas- a nivel de noticia nacional. El epitafio de Griselda al final añade otra capa más a las tres historias de Malén, Vilma y Carola (y Maité). El nombre de su editorial “Ediciones Seremos” sugiere el “venceremos” revolucionario -la lucha continua-, al igual que la creencia de que las mujeres pueden recuperar las voces perdidas a través de la escritura.

\section{Detectives góticos}

El género gótico y el género negro se consideran "literatura escapista”, pero permiten la investigación de cerca del elemento bárbaro en la sociedad humana. Este elemento se expresa en la novela gótica mediante la pasión y violencia atribuidas por las culturas anglosajonas a las culturas latinas, y por la metrópoli a la colonia. Los personajes caribeños de Ana Lydia Vega en "Pasión de historia" son, hasta cierto punto, caricaturas de estos atributos, pero la barbarie real se encuentra por igual en las Antillas y en la burguesía europea. Sin embargo, en "Ajustes, S.A.", lo gótico y lo negro se confinan al contexto puertorriqueño, dejando a un lado la crítica anticolonial para investigar de cerca la cuestión genérica.

“Ajustes, S.A.”, es una agencia detectivesca dedicada a la reivindicación de la dignidad femenina en una sociedad machista. Las mujeres operativas de la agencia tienen apodos que demuestran la intensidad con la que se desempeñan en esta tarea: Bárbara evoca la devoradora de hombres de la novela telúrica; Porcia, la heroína valiente que se viste de macho para resolver un misterio y salvar al hombre débil; Medea, la arquetípica mujer vengativa y Circe, que transformó a los marineros en cerdos para comerlos.

El dramático “Expediente 6000” es el caso del Marido Ideal, cuya perfección en asuntos domésticos y matrimoniales arremete contra la auto estima de su mujer. Ella les pide a las socias de la agencia que le busquen una excusa para divorciarse del "Penable". Tras una serie de fútiles asaltos contra la virtud y paciencia del

Revista Iberoamericana, Vol. LXXVI, Núm. 231, Abril-Junio 2010, 443-457
ISSN 2154-4794 (Electrónico) 
hombre, las mujeres se dan por vencidas y le pasan el expediente a la jefa suprema de la organización. El final es tan inevitable como perverso: "La Suprema Socia Benefactora” resulta ser el Marido Ideal y les ordena quemar el expediente y silenciar a la clienta, su mujer.

Es importante recordar que todas las mujeres arquetipos homónimos de las investigadoras fueron derrotadas o "neutralizadas” por un hombre: Doña Bárbara por Santo Luzardo; Porcia por su matrimonio con Bassanio; Medea, abandonada por Jason y Aegeus, huyó de la civilización y Circe fue seducida por Ulises. Todas estas figuras femeninas -mujeres valientes y perspicaces, brujas poderosas, y diosas inmortales- fueron vencidas por hombres mortales a pesar de sus capacidades extraordinarias.

Lo gótico de este cuento radica en la imagen de la mano negra del hombre (el Marido Ideal lleva tres sortijas negras en los dedos) detrás de las mujeres, vigilando y controlando todas sus actividades feministas. El humor del cuento es un humor totalmente negro, dado que le niega absolutamente la agencia a la mujer, incluso en sus más dedicadas empresas. El resultado final es un perfil de la mujer -como especie-perdida en un laberinto de valores perversos. La Clienta no habría visitado la agencia si no fuera por su necesidad de abnegarse en el matrimonio, lo cual se le negaba por la perfección del esposo. La imposibilidad de así "realizarse" como mujer en un sistema machista la impulsó a buscar la libertad, y fue este impulso que llevó a su presunto asesinato a manos de sus protectoras. Este asesinato de una mujer por otras mujeres refleja el asesinato de la virtud de Malén, cometido por las mujeres del vecindario.

\section{ConCLUSIÓN}

En los cuentos de Pasión de historia y otras historias de pasión, el femicidio se revela como una realidad inevitable y constante de la sociedad patriarcal. La pregunta de Anderson Imbert sobre la relevancia de la ficción criminal sugiere que la muerte violenta es aceptable en Latinoamérica. Mientras que la novela negra norteamericana generalmente termina con una restauración de la justicia (incluso si el proceso de esta restauración viola la ley u otra norma social, o, también si exacerba el desengaño del detective), en la novela negra hispanoamericana no existe ninguna garantía fuera del caos. En la novela gótica tradicional, hay un final feliz para la protagonista. Las normas patriarcales se reafirman mediante el matrimonio con el amo, la recuperación de la fortuna perdida u otro mecanismo que reinserta a la heroína en la jerarquía social burguesa. En Pasión de historia y otras historias de pasión, lo gótico y lo negro se invocan mutuamente para afirmar que la propia tela social es, en efecto, un sudario para la mitad de la población. Sólo a través de esta unión es posible representar esta enajenación vital de la mujer.

Revista Iberoamericana, Vol. LXXVI, Núm. 231, Abril-Junio 2010, 443-457
ISSN 2154-4794 (Electrónico) 
BiBLIOGRAFÍA

Alberty Fragoso, Carlos. "Nación e Ironía en Sobre tumbas y héroes de Ana Lydia Vega”. Exegesis 10/29 (1997): s.p. <http://www.uprh.edu/exegesis/ano10/29/ Alberty_Fragoso.html>

Anderson Imbert, Enrique. "The General Makes a Lovely Corpse”. Latin Blood. The Best Crive and Detective Stories of South America. Donald Yates, ed. Nueva York: Herder and herder, 1972. 149-172.

Anolik, Ruth Bienstock y Douglas L. Howard. The Gothic Other: Racial and Social Construction in the Literary Imagination. Jefferson: McFarland, 2004.

Benjamin, Walter. Poesía y capitalismo. Iluminaciones II. Madrid: Taurus, 1980. Boling, Becky. "The Reproduction of Ideology in Ana Lydia Vega's 'Pasión de historia' and 'Caso omiso'”. Letras Femeninas 17/1-2 (primavera-otoño 1991): 89-97.

Brontë, Charlotte. Jane Eyre. Nueva York: Norton, 2001.

Cisneros Morales, Jorge. “La novela negra, en su mayoría de edad”. El Nacional (18 julio 1997).

Craig, Linda. “Intersections in Ana Lydia Vega’s ‘Pasión de historia'”. MaComère: Journal of the Association of Caribbean Women Writers and Scholars 4 (2001): 71-83.

DaVinci Nichols, Nina. "Place and Eros in Radcliffe, Lewis, and Brontë”. The Female Gothic. Montreal: Eden Press, 1983. 187-206.

Dougherty, Stephen. "National Bodies: Blood and Sexuality in Poe’s Gothic Horror”. $<$ http://prometheus.cc.emory.edu/panels/1C/S.Dougherty.html>

Ferré, Rosario. Maldito amor. México: Porrúa, 1986.

Galván, Delia V. "Sincretismo cultural en estructura policíaca: Ana Lydia Vega y su Pasión de historia”. Americas Review 21/3-4 (otoño-invierno 1993): 139-49.

Hernández, Elizabeth y Consuelo López Springfield. "Women and Writing in Puerto Rico: An Interview with Ana Lydia Vega”. Callaloo: a Journal of African American and African Arts and Letters 17/3 (verano 1994): 816-25.

Jameson, Fredric R. "On Raymond Chandler”. The Poetics of Murder. Glen W. Most y William W. Stowe, eds. Nueva York: Harcourt, Brace, 1983.

Myers, Helene. Femicidal Fears. Narratives of the Female Gothic Experience. Albany: SUNY P, 2001.

Prendergast, Kathy. "The Gothic Tradition”. <http://www.usask.ca/english/frank/ gothtrad.htm>

Richardson, Samuel. Clarissa. Angus Ross, ed. Nueva York: Penguin, 1985.

Revista Iberoamericana, Vol. LXXVI, Núm. 231, Abril-Junio 2010, 443-457
ISSN 2154-4794 (Electrónico) 
Rosell, Sara. “La detectivesca femenina posmoderna: El caso de 'Pasión de historia' y Nuestra Señora de la Soledad”. Explicación de Textos Literarios 30/1-2 (2001-2002): 94-103.

Sáez, Hugo Enrique. “La nota roja chic”. Cuadernos Patafísicos. México: UAMXochimilco, 1992. 93-99.

Vega, Ana Lydia. Pasión de historia y otras historias de pasión. Buenos Aires: De la Flor, 1987.

Falsas crónicas del Sur. Río Piedras: Universidad de Puerto Rico, 1991.

Velez, Diana. “Ana Lydia Vega’s ‘Pasión de historia’: A Text Within Two Genres”. Torre de Papel 14/1-2 (primavera-verano 2004): 44-51.

Waller, Debra G. “Jane Eyre and Fanny Price”. <http://www.victorianweb.org/ authors/bronte/cbronte/waller2.html>

Winter, Kari. “Sexual/Textual Politics of Terror”. Misogyny in Literature: An Essay Collection. Nueva York: Garland, 1992. 89-101.

$\begin{array}{llllll}\text { Revista Iberoamericana, Vol. LXXVI, Núm. 231, } & \text { Abril-Junio 2010, 443-457 } \\ \text { ISSN 0034-9631 (Impreso) } & \text { ISSN 2154-4794 (Electrónico) }\end{array}$ 
